\title{
MERCER'S INEQUALITY AND TOTALLY MONOTONIC SEQUENCES
}

\section{GRAHAME BENNETT}

Abstract. A simple inequality of Mercer leads to some intriguing problems concerning moment sequences.

Mathematics subject classification (2010): 44A60, 26D15, 40G05.

Keywords and phrases: Moment sequence, Hausdorff mean, convex sequence, unimodal sequence.

\section{REFERENCES}

[1] M. Abramowitz And I. A. STegun, Handbook of mathematical functions with formulas, graphs, and mathematical tables, National Bureau of Standards Applied Mathematics Series, Vol. 55, National Bureau of Standards, Washington, D.C., 1966.

[2] N. I. Ahiezer And M. Krein, Some questions in the theory of moments, Translations of Mathematical Monographs, Vol. 2, Amer. Math. Soc., Providence, 1962.

[3] G. Bennett, Monotonicity-preserving matrices, Analysis (Munich), 24 (2004), 317-327.

[4] G. BenNetT, Hausdorff means and moment sequences, Positivity, 15 (2011), 17-48.

[5] F. BRENTI, Log-concave and unimodal sequences in algebra, combinatorics, and geometry: an update, Jerusalem Combinatorics, 93, 71-89, Contemp. Math. 178, Amer. Math. Soc., Providence, 1994.

[6] S. Dharmadhikari And J.-D. Kumar, Unimodality, convexity, and applications, Probability and Mathematical Statistics, Academic Press, Boston, 1988.

[7] I. GAVREA, Some remarks on a paper by A. McD. Mercer, J. Inequal. Pure Appl. Math., 6, 1 (2005), Art. 26, http://jipam.vu.edu.au/article.php?sid=495.

[8] R. L. Graham, D. E. Knuth and O. Patashnik, Concrete Mathematics, Addison-Wesley, Reading, 1990.

[9] G. H. Hardy, Divergent Series, Chelsea Publ. Co., New York, 1991.

[10] G. H. Hardy, J. E. Littlewood and G. Pólya, Inequalities, Cambridge University Press, Cambridge, 1967.

[11] S. Karlin, Total Positivity, Vol. I, Stanford University Press, Stanford, 1968.

[12] S. KARLIN AND W. J. STUDDEN, Tchebycheff systems: with applications in analysis and statistics, Pure and Applied Mathematics, Vol. XV, Interscience Publishers, John Wiley and Sons, New York, 1966.

[13] E. Laguerre, Oeuvres, Chelsea Publ. Co., New York, 1973.

[14] V. I. Levin And S. B. SteČKin, Inequalities, Amer. Math. Soc. Transl. (2), 14 (1960), 1-29.

[15] A. McD. Mercer, A note on a paper by S. Haber, Internat. J. Math. and Math. Sci., 6 (1983), 609-611.

[16] A. MCD. Mercer, Polynomials and convex sequence inequalities, J. Inequal. Pure Appl. Math., 6, 1 (2005), Art. 8, http://jipam.vu.edu.au/article.php?sid=477.

[17] G. Pólya AND G. Szegö, Problems and Theorems in Analysis II, Springer Verlag, New York, 1976.

[18] W. Rudin, Real and Complex Analysis, McGraw-Hill, New York, 1966.

[19] T. A. Shohat And J. D. Tamarkin, The Problem of Moments, Amer. Math. Soc., Waverly Press, New York, 1943.

[20] D. V. WidDER, The Laplace Transform, Princeton University Press, Princeton, 1941. 